\title{
Condições de trabalho na Estratégia de Saúde da Família: relato de experiência de extensão universitária com agentes comunitários de saúde
}

\author{
Jaquelina Maria Imbrizi, \\ Fernanda Braz Tobias de Aguiar ${ }^{\mathrm{II}}$, Aline Fajardo, \\ Janaína Hatsue Barrozo Hirata ${ }^{I}$, Karina Kawagoe ${ }^{\mathrm{I}}$ e Aurélio Keiji Miyaura ${ }^{\mathrm{I}}$ \\ ${ }^{1}$ Universidade Federal de São Paulo (Santos, SP) \\ ${ }^{\text {II }}$ Programa de Aprimoramento Profissional em Saúde Coletiva do Hospital das Clínicas, Faculdade de \\ Medicina da Universidade de São Paulo (São Paulo, SP)
}

\begin{abstract}
É sabida a importância de novos cenários de aprendizagem para a formação do profissional de saúde. A partir da interação da universidade com regiões de vulnerabilidade de Santos-SP, e seus serviços, foi criado o projeto de extensão universitária "A potencialização da capacidade de ação dos agentes comunitários de saúde" como um espaço de escuta e elaboração de vivências para os agentes comunitários de saúde (ACS) de uma dessas regiões. $\mathrm{O}$ objetivo deste artigo é dar visibilidade a condições de trabalho dos ACS por meio dos diários de campo produzidos durante o projeto de extensão universitária. Trata-se de uma análise dos registros feitos pelos estudantes na perspectiva de dar voz à experiência e à percepção dos ACS sobre seu trabalho em uma unidade da Estratégia de Saúde da Família (ESF), a partir da qual se construíram seis analisadores. Por fim, a partir das condições de trabalho dos ACS, verificou-se a importância da construção de outro lugar para esses profissionais na equipe, da promoção de uma maior interação dentro da própria equipe e de dedicar um olhar mais cuidadoso à capacitação desses profissionais, para a construção e o fortalecimento da ESF.
\end{abstract}

Palavras-chave: Agentes comunitários de saúde, Saúde da família, Condições de trabalho, Formação profissional.

Work conditions in the Family Health Strategy: report of an experience of university extension with community health agents

The importance of new learning scenarios for the health professional's training is well-known. Through the university's interaction with vulnerable regions of Santos, Sao Paulo, Brazil, and their services, the university extension project named "Potentiation of the community health agents' action capacity" was created as a space for listening and preparing experiences for the community health agents (CHAs) from one of these areas. This paper aims to provide visibility to the work conditions of CHAs by means of the field diaries produced during the university extension project. This is an analysis of records made by the students under the perspective of giving voice to the experience and perception of CHAs on their work in a Family Health Strategy (FHS) unit, through which six analyzers were developed. Finally, through the CHAs work conditions, it was possible to determine the importance of creating a new place for these professionals in the team, promoting a greater interaction within the team itself, and dedicating a more careful look at these professionals' training, for the development and strengthening of FHS.

Keywords: Community health agents, Family health, Work conditions, Professional training.

\section{Introdução}

$\mathrm{O}$ Projeto Político Pedagógico da Universidade Federal de São Paulo (Unifesp), campus Baixada Santista, objetiva a formação interprofissional para atuação no Sistema Único de Saúde (SUS). Um dos eixos desse projeto se chama Trabalho em Saúde e dá prioridade a situações de aprendizagem nas quais os alunos dos seis cursos de graduação, (Educação Física, Fisioterapia, Nutrição, Psicologia, Serviço Social e Terapia Ocupacional) visitam regiões de vulnerabilidade social para reconhecer território, produzir narrativas de história de vida e elaborar projetos interdisciplinares de intervenção a partir de visitas domiciliares. 
Os domicílios a ser visitados são indicados pelos agentes comunitários de saúde (ACS) aos docentes da universidade e escolhidos em reuniões das quais também participam os alunos e a coordenadora da equipe de saúde. Procura-se selecionar as famílias que mais se beneficiariam das atividades propostas pelos professores da graduação.

Nessas reuniões, surgiu uma demanda específica do grupo de ACS, que reivindicava um espaço de escuta e de cuidado em função das dificuldades diárias que enfrentavam. Pode-se afirmar que essa é uma demanda de todos os lugares visitados, mas foi em uma das unidades da Estratégia de Saúde da Família (ESF) da região dos Morros, na cidade de Santos, que os agentes se queixaram e pediram para ser ouvidos pela equipe da universidade.

Surgiu assim o projeto de extensão universitária A potencialização da capacidade de ação dos agentes comunitários de saúde (Castro-Silva, Imbrizi \& Garcia, 2009-2011), que transcorreu de agosto de 2009 a junho de 2011, promovendo o requerido espaço de escuta, acolhimento e elaboração de vivências desencadeadas na atuação dos ACS, potencializando sua ação com vistas à promoção da saúde da população. $O$ projeto consistiu de reuniões semanais com temas baseados nas demandas dos ACS e cada reunião foi registrada em diário de campo por duplas de alunos do curso de Psicologia.

O objetivo deste artigo é apresentar e analisar o que foi produzido nesses diários de campo para dar a conhecer as condições de trabalho dos ACS e evidenciar a importância de dar voz à percepções desses trabalhadores sobre a ESF.

\section{Sobre o método}

Partindo da indissociabilidade entre ensino, pesquisa e extensão, compartilhamos experiências com o grupo de ACS, registramos o que eles relataram e produzimos os diários de campo, que consistiram em notas descritivas e intensivas ${ }^{1}$ : observações, impressões, falas literais e análise da interação dos ACS entre si e com a equipe da universidade. Desde o início, estávamos atentos ao alerta de Caiafa (2007, p. 154): "Em nossos encontros no campo, como na vida, não seria questão de nos fundirmos com os outros ou nos distanciarmos para julgá-los ou descrevê-los, mas de compartilhar a paixão com eles, experimentar simpatia".

O que apresentamos, aqui, são registros dos 12 encontros que ocorreram durante o projeto de extensão entre junho e novembro de 2009, primeiro semestre de atividades, de que participaram 12 ACS, 7 estudantes e 4 docentes. Da equipe da universidade, apenas 1 docente e 5 estudantes dispuseram-se a escrever e publicar os resultados do projeto de extensão e, para tanto, houve reuniões quinzenais ao longo de 18 meses. Nesses encontros, distribuíamos as atividades de leitura dos diários de campo e anotação do que se sobressaía e discutíamos as notas e os achados de cada um, procurando pontos comuns, inusitados ou contraditórios presentes no registro das falas dos ACS sobre seu cotidiano de trabalho.

Nesse sentido, os produtos do projeto de extensão foram transformados em dados para uma pesquisa que visou a praticar o método da cartografia, no qual se produzem dados no decorrer do processo, em função da indissociabilidade entre pesquisa e intervenção, sujeito e objeto e teoria e prática. Os pesquisadores estão implicados no processo, e há uma ênfase no trabalho coletivo de produção de conhecimento. Assim, houve aproximação ao "[...] método cartográfico, segundo o qual o trabalho da análise é a um só tempo o de descrever, intervir e criar efeitos-subjetividade" (Passos, Kastrup \& Escóssia, 2009, p. 27).

Essas análises foram sintetizadas em seis tópicos chamados analisadores ${ }^{2}$. Para Passos e Barros (2000), que se utilizam de um conceito-ferramenta formulado por Felix Guatarri, 
analisadores são acontecimentos que assinalam as múltiplas relações que ocorrem no plano da experiência da pesquisa, de modo a se considerar a intervenção e o como ela se constitui e, além disso, analisam as implicações institucionais e o lugar que ocupa o pesquisador. Os tópicos não foram dispostos cronológica ou hierarquicamente, pois são interarticulados, mas de modo a acompanhar o processo da elaboração e produção escrita do texto (Passos et al., 2009) e facilitar a compreensão do leitor. Os seis analisadores construídos são: 1) $O$ peso do assistencialismo e da religião no trabalho dos ACS: empecilho à autonomia e ao cuidado de si; 2) Hierarquia na ESF: a defasagem entre o trabalho prescrito e o trabalho real; 3) Trabalho afetivo e produção de subjetividade; 4) Tão longe e tão perto: as dimensões profissional e pessoal na vida do ACS; 5) Precarização do trabalho do ACS: capacitação, plano de carreira e projeto de vida; e 6) Quem cuida dos profissionais cuidadores?

Num segundo momento, cada analisador foi novamente articulado com trechos dos diários de campo e problematizado por meio da pesquisa e leitura de artigos científicos e livros sobre o tema. Nesse sentido, não nos preocupávamos com a aplicação de uma teoria, mas com a produção de conhecimentos a partir da experiência que se desenvolvia no presente.

Inspirados pelas ideias de Kastrup (2008, p. 94), o que buscamos valorizar no tempo presente não é o que é específico e datado, mas, sim, sua imprevisibilidade e seu "estatuto de campo movente". Aproximamo-nos, assim, de uma ontologia do presente, que, segundo Adverse (2010, p. 150), é uma expressão utilizada por Michel Foucault para definir a natureza de seu trabalho filosófico, que "[...] não se trata de um receituário filosófico, trata-se, antes, de abalar a universalidade daquilo que é reconhecido como óbvio no tempo atual como estratégia para promover outras formas de subjetividade".

Passemos, pois, à apresentação dos analisadores.

\section{O peso do assistencialismo e da religião no trabalho dos ACS: empecilho à autonomia e ao cuidado de si}

A fala que se sobressaiu no registro da primeira reunião do grupo se referia ao perfil profissional do ACS: "[...] o quanto o profissional de saúde necessita ser um pouco "Madre Tereza de Calcutá', como pré-requisito para essa profissão [...]” (reunião, 25 jun.).

A referência ao assistencialismo aparece nessa analogia entre a característica necessária ao exercício da profissão de ACS e o estereótipo ligado à missionária católica Madre Tereza de Calcutá - que fez voto de castidade e de pobreza, dedicou a vida ao trabalho social em diferentes países e era reconhecida por sua grande bondade e fé em Deus. É possível que essa menção esteja ligada à região onde atuam esses ACS: os morros da cidade de Santos são áreas de ocupação, onde as condições de moradia são, muitas vezes, precárias e a maioria da população vive em casas de madeirite. É um lugar geograficamente isolado, distante das áreas centrais e da orla, em que há pouco exercício dos direitos do cidadão e poucos espaços de convivência coletiva, o que dificulta o acesso da população a políticas públicas sociais e de saúde, a atividades culturais e a lazer.

Faz-se referência à religião em várias falas de agentes, nas quais o poder divino parece substituir intervenções que poderiam aumentar o grau de autonomia dos munícipes e dos próprios agentes. Por exemplo, diz a agente A.: "[...] quando estava com pressão alta, preferiu entregar na mão de Deus do que tomar os remédios ou fazer as consultas e relata que ficou bem" (reunião, 16 nov.).

2 Para Passos e Barros (2000, p. 76), os analisadores são "acontecimentos - no sentido daquilo que produz rupturas, que catalisa fluxos, que produz análise, que decompõe”. 
A partir dessa fala da ACS, trata-se de investigar o papel da crença religiosa na vida desses profissionais, ou seja, essa crença pode estar na cultura tanto do ACS quanto dos munícipes e molda certa concepção do processo saúde-doença-cuidado que independe das ações da equipe de saúde e pode impedir o exercício do cuidado de si, seja de uns ou de outros.

Cabe ressaltar que a atuação vinculada ao assistencialismo e/ou a crenças religiosas pode fortalecer certos automatismos nas práticas em saúde. Lara Junior e Ribeiro (2009, p. 92) alertam para a diferença entre atuar "sobre" a comunidade e atuar "com" a comunidade. Essa atuação estaria associada à partilha das dificuldades que visa a criar estratégias de superação junto com as pessoas da comunidade. Aí estaria a possibilidade de exercício da autonomia e da cidadania dos munícipes.

Os autores afirmam que atuar "sobre" a comunidade diz respeito ao par complementar vitimização $\times$ opressão, inerente às relações sob a lógica da sociedade capitalista e associado por excelência ao assistencialismo, o que implica, por um lado, colocar-se no lugar de quem tem a dar e, por outro, apresentar-se como detentor de um saber que ensinará ao povo (Lara Junior \& Ribeiro, 2009, p. 92).

Foi possível perceber essa demanda implícita do ACS em relação à equipe da universidade: "[...] A. perguntou se nós não poderíamos dar opiniões sobre o que elas relatavam. [...] ela gostaria que déssemos conselhos [...] que disséssemos se isso ou aquilo era certo ou errado" (reunião, 9 out.).

Quanto à relação com os ACS, os munícipes insistiam que eles agissem em seu lugar, e não a seu lado: "É legal sermos conhecidas por morarmos aqui, mas outra coisa é achar que temos que atendê-los 24 horas por dia" (reunião, 21 set.).

Essa questão pode ser associada à fala de um dos ACS: "[...] Al. disse que é difícil, porque os munícipes acham que elas têm a obrigação de cuidar deles [...] sente dificuldade de colocar na mente deles que são eles que têm que se autocuidar" (reunião, 2 set.). Parece que o que a ACS chama de autocuidado é o que Cecílio (2001, pp. 114-115) aponta como um dos quatro grandes conjuntos de necessidades de saúde: a possibilidade de graus crescentes de autonomia do sujeito, que "[...] implicaria a possibilidade de reconstrução, pelos sujeitos, dos sentidos de sua vida, e essa ressignificação ter peso efetivo no seu modo de viver, incluindo aí a luta pela satisfação de suas necessidades, da forma mais ampla possível".

Segundo o autor, esse aspecto depende de outros três grandes conjuntos de necessidades: o acesso a boas condições de vida, o acesso a toda tecnologia de saúde capaz de melhorar e prolongar a vida e a insubstituível criação de vínculos afetivos e efetivos entre cada usuário e uma equipe ou profissional de saúde. Portanto, é possível localizar na fala dessa ACS a "obrigação" de cuidar dos munícipes e a dificuldade de esclarecê-los sobre a importância do cuidado de si. Nesse sentido, o trabalho de cuidar e de estabelecer vínculos se torna um peso para esse profissional de saúde. Para atenuar esse peso, cabe oferecer ao ACS uma formação em que se discutam as necessidades em saúde, pois, como alerta Cecílio (2001), só é possível exercitar o cuidado de si quando os três conjuntos de necessidades de saúde estão contemplados, o que não parece ser o caso dessa população.

Nesse sentido, notamos que, ao se referir ao Programa Bolsa Família, um dos ACS percebe esse dispositivo como uma doação, e não como direito do cidadão a melhores condições de vida: " $K$. disse que o Lula [...] fica esmolando 50 reais por família [...] que o presidente acha que, dando coisas às pessoas, vai melhorar a vida delas, mas ela acha que não" (reunião, 2 set.).

Um ponto importante a destacar é a dimensão política do trabalho do ACS, pois, com a implantação da Política Nacional da Assistência Social (Brasil, 2004), a legislação brasileira ganhou novos embasamentos para o exercício de direitos do cidadão ao vincular a assistência social à política de proteção social. Segundo o texto oficial: "Muitos, às vezes e ainda, confundem a assistência social com clientelismo, assistencialismo, caridade ou ações pontuais, 
que nada têm a ver com políticas públicas e com o compromisso do Estado com a sociedade" (Brasil, 2004, p. 12). A hipótese é que os ACS não estão sendo preparados pela ESF para inserir a discussão dessa legislação em sua profissão, posto que confundem assistencialismo com as políticas públicas de assistência social que visam a contribuir para o fortalecimento dos munícipes. No entanto, uma das atribuições importantes do profissional ACS é conhecer essa legislação, que depende do acesso a informações sobre as políticas públicas de saúde e sociais, da capacidade de interpretá-las e de implantá-las em prol e junto à comunidade em que atuam, de modo a criar estratégias para que se alcancem melhores condições de vida e de saúde.

Outra estratégia política que faz parte da atuação do ACS é a identificação e o fortalecimento de redes de apoio existentes entre o cidadão, as lideranças, as associações e as famílias da comunidade. Para resolver um caso, por mais simples que ele seja, o ACS precisa ter conhecimento dessas redes sociais e saber acessar informações sobre os trâmites burocráticos do SUS e do Sistema Único da Assistência Social (SUAS), além de identificar pessoas de referência nessas instâncias; só assim poderá empreender ações intra e intersetoriais. K. afirmou que existem muitos tipos de auxílio: "[...] a mãe que tem bolsa auxílio família ganha um saláriomínimo. Como também tem o auxílio gás, a pessoa vai até a assistente social [...] e paga metade do gás". Em outro registro, uma ACS se dá conta de que foi incorporando esses conhecimentos na sua atuação cotidiana: "[...] eu era uma pessoa ignorante, não sabia que existiam esses recursos" (reunião, 28 set.).

Em algumas falas, foi possível notar certo descrédito do ACS diante das políticas públicas e da resposta demorada ou ausente aos grandes problemas do cotidiano dos munícipes que são apresentados e discutidos em reuniões de equipe e encaminhados às diferentes instâncias de apoio: "[...] Ac. diz que em algum momento essa rede se quebra [...] que é quando chega aos grandes órgãos" (reunião, 16 nov.). Parece que esse descrédito está associado às questões burocráticas, que emperram a resolução do processo. Tal burocracia não é prerrogativa exclusiva da ESF, mas se faz sentir em toda a rede do SUS. Preocupados com as relações entre a atenção básica a saúde (ABS) e a ESF, Campos, Gutiérrez, Guerreiro \& Cunha (2008, p. 137) afirmam:

[...] existe forte relação entre esses dois campos: políticas de saúde e características das unidades de saúde. São talvez campos distinguíveis, mas não separáveis. Um campo geral das políticas de saúde (e até das políticas públicas sociais), próximo das características de sistema, e outro da gestão e das práticas dos serviços de saúde, mais próximo das características das unidades de saúde [...]. No Brasil, há dificuldade com a ABS nesses dois campos, tanto no da gestão e das práticas clínicas, quanto no mais amplo, da política do SUS.

No que se refere à gestão e às práticas de saúde, foi possível perceber que há uma defasagem entre o trabalho prescrito e o trabalho real ${ }^{3}$ do ACS. Ao fazer essa distinção, Dejours (1999) visa a valorizar o fato de que o trabalhador mobiliza sua criatividade e invenção para dar conta daquilo que não foi previsto pela organização prescrita do trabalho, mas, muitas vezes, esse esforço não é reconhecido pelos chefes e pelos pares no momento em que essas ações ocorrem. A falta de reconhecimento pode levar a certo descrédito e à desmobilização do trabalhador para sua contribuição no processo de trabalho. No caso dos ACS, incide diretamente sobre a qualidade da atenção oferecida aos usuários dos serviços de saúde. É dessa questão que trata o segundo analisador.

\footnotetext{
3 Segundo Dejours (1999, pp. 42-43): "O trabalho é a atividade coordenada desenvolvida por homens e mulheres para enfrentar aquilo que, em uma tarefa utilitária, não pode ser obtido pela execução estrita da organização prescrita. Essa definição contém três noções propostas para caracterizar o trabalho, mas considera de modo mais preciso o real: aquilo que em uma tarefa não pode ser obtido pela execução rigorosa do prescrito. E também incide sobre a dimensão humana do trabalho: é aquilo que deve ser ajustado, rearranjado, imaginado, inventado, acrescentado pelos homens e pelas mulheres para levar em conta o real do trabalho".
} 


\section{Hierarquia na ESF: a defasagem entre o trabalho prescrito e o trabalho real}

O trabalho prescrito diz das atribuições oficiais dos ACS, definidas no Decreto n. 3.189, de 4 de outubro de 1999: "Atividades de prevenção de doenças e promoção da saúde, por meio de ações educativas individuais e coletivas, nos domicílios e na comunidade, sob supervisão competente" (Brasil, 1999). A profissão foi criada pela Lei n. 10.507, de 10 de julho de 2002 (Brasil, 2002).

Essas atividades estão diretamente relacionadas ao território geográfico e existencial das pessoas que compõem o entorno da unidade da ESF. Para Furlan (2008), é esperado que o profissional construa um vínculo forte e ampliado entre comunidade e serviços. Ou seja, seria responsabilidade da ESF aumentar a capacidade da população para "cuidar da própria saúde e resolver seus próprios problemas, sendo o ACS um facilitador deste processo" (Furlan, 2008, p. 369).

Ao compor a equipe básica de uma unidade da ESF, o diferencial do ACS, entre outros também importantes, é ser próximo da comunidade. Essa proximidade deveria estar centrada na identificação das necessidades de saúde dos munícipes e de seus desejos e na inserção de um saber que difere do biomédico, pois, como alerta Conill (2008, p. 14), desde 1994, a ESF é considerada "uma estratégia para reorientação do modelo assistencial com caráter substitutivo das práticas convencionais"; nesse sentido, é uma estratégia que nasce da resistência ao modelo médico assistencial e está vinculada à "[...] incorporação de práticas de territorialização, maior vínculo, envolvimento comunitário e acompanhamento de prioridades programáticas, o que é coerente com o cumprimento de seu referencial normativo".

Para identificar os problemas de saúde e sociais que acometem a população, os ACS fazem visitas domiciliares ${ }^{4}$ e deveriam estar capacitados para compreender e analisar os modos de vida e oferecer atividades com vistas à criação de espaços de troca na comunidade e à formação de grupos para transmissão do conhecimento técnico-científico e educação em saúde (Furlan, 2008).

O ACS reconhece que não tem formação ou preparo em técnicas de recrutamento, formação e coordenação dos grupos: "O ESF determina que os ACS façam trabalho no campo e formem grupos para promover a saúde, mas na realidade isso não acontece”, em decorrência do despreparo técnico do ACS, como também da dificuldade de os munícipes aderirem à proposta de grupos de atenção à saúde na comunidade: "M. diz que não consegue formar grupos com os munícipes, pois eles não comparecem" (reunião, 19 out.). Assim, o ACS pede à equipe da universidade que o ajude a formar esses grupos: "[...] gostariam que nós as auxiliássemos com a formação de grupos e as ajudássemos a lidar com a frustração, caso não haja adesão das pessoas da comunidade ao grupo" (reunião, 30 nov.).

O que se pôde perceber pelo registro das falas dos ACS é que o exercício dessas atribuições prescritas vem sendo obstado em decorrência do pequeno número de funcionários que compõem a unidade, do grande número de famílias acompanhadas e do acúmulo de atividades administrativas.

Quanto ao número reduzido dos funcionários que compõem a equipe da unidade da ESF, registrou-se nas falas dos ACS que, se um funcionário goza de férias, sobrecarrega a equipe em exercício: "M. relata estar fazendo serviço da área de E. [que está de férias]. Ela se preocupou com uma senhora e foi entregar o encaminhamento a ela num dia de chuva, mas esta nem apareceu na consulta". Nessa situação, M. relata "um sentimento de raiva e a percepção do quanto o seu

4 Segundo a política de atenção básica, a visita domiciliária é uma atribuição não só do ACS, mas de todos os profissionais da equipe de saúde, quando necessária ao cuidado da saúde da população (Brasil, 2006). Porém, na unidade de saúde em que foi realizado o projeto de extensão, apenas os ACS visitavam as famílias cadastradas. 
trabalho está sendo desvalorizado". O que acaba por moldar certa percepção das políticas de saúde: "M. acha que a ESF foi criada para a prefeitura economizar e não contratar mais funcionários" (reunião, 31 ago.).

O fato de haver muitas famílias atendidas - cerca de 150 por ACS, aumentando cada vez mais e acrescido do grande número de pessoas por família - leva o ACS a reduzir o número de visitas domiciliares, o que pode afetar a qualidade da atenção à saúde da população. Outra dificuldade enfrentada pelo ACS é o assédio dos munícipes quando ele está desenvolvendo atividades no território: "Cinco pessoas me pararam até o caminho da escola, não consigo ser grossa' [...] diz que há muitas pessoas procurando por ela [...]". E complementa com a queixa de que os munícipes "Não vão ao posto cobrar, eles cobram a gente!". Por fim, conclui: "Esse é um dos motivos pelos quais sente vontade de desistir" (reunião, 31 ago.).

No que se tange às atividades administrativas, os ACS se queixam de que, na prática, na maioria das vezes, funcionam como entregadores que levam e trazem as informações entre o munícipe e o posto de saúde: "Ela confessa que [...] se sente uma office girl, quebra-galho" (reunião, 31 ago.). Os agentes percebem que essas não são suas atividades, mas há duplicação de suas tarefas: "Ac. relata que, por causa das atividades administrativas, elas têm que ficar no posto e, assim, para não deixar de fazer as visitas domiciliares, efetivamente [...] fazem dois trabalhos para entregar a sua produção para a prefeitura" (reunião, 31 ago.).

Pela fala dos ACS, percebeu-se rigidez na agenda de tarefas que, muitas vezes, o agente não tem autonomia para mudar: "[...] Ke. lembrou que, se elas não passam no posto logo cedo, as pessoas ficam cobrando, o posto liga na casa delas para cobrar o comparecimento, porque não passaram lá. M. completou [...] dizendo que são vigiadas" (reunião, 28 set.). Isso ainda em decorrência das relações hierarquizadas na organização do trabalho: "O que eu posso fazer eu faço; eu não posso morrer por causa de ninguém" (reunião, 16 nov.). Mostram-se, assim, mais absorvidos pela burocracia, no exercício de suas atividades, e as visitas domiciliares se reduzem a tarefas como a entrega de remédios e informações sobre datas de exames e consultas e o recolhimento da assinatura do munícipe na planilha de visitas: "K. diz que importância até elas têm, mas as atividades que exercem se tornaram corriqueiras" (reunião, 19 out.). A agente M. parece ter uma postura mais crítica diante da ênfase no controle das assinaturas: "[...] a preocupação só com as assinaturas é muito mecânica" (reunião, 23 nov.).

Furlan (2008) e Schmidt e Neves (2010) confirmam o predomínio desse tipo de lógica burocrática e produtivista que impregna o exercício profissional do ACS. Para Furlan (2008, p. 373), infelizmente, as ações dos ACS: “[...] são prioritariamente referentes à vigilância epidemiológica, centradas em atividades de controle e saneamento, e reprodutoras de atividades existentes há anos no local". Para Schmidt e Neves (2010, p. 229): “[...] a prática do agente comunitário é capturada pela prevalência do modelo médico-assistencial no interior de um programa que tenta superá-lo".

O que nos leva a constatar que o trabalho real dos ACS está vinculado a toda e qualquer atividade demandada pela equipe de saúde e pelos munícipes e, consequentemente, a agente M. afirma que: "[...] gosta de se sentir útil e que a equipe precisa da sua presença, mas que seus serviços não são valorizados. [...] faz tarefas que não estão ligadas a sua função [...]" (reunião, 17 ago.).

Nunes, Trad, Almeida, Homem e Melo (2002, p. 1641) avaliam que essa desvalorização também está associada ao fato de que a sobrecarga de trabalho não é acompanhada por um aumento da remuneração desses trabalhadores: "A inclusão do ACS no ESF representa também, segundo vários relatos, um aumento significativo de trabalho e de responsabilidade, sem que isso seja acompanhado de aumento salarial correspondente". O resultado da pesquisa realizada por esses autores confirmou a posição inferiorizada dos ACS diante do salário dos outros profissionais de saúde: "[...] três, entre os cinco municípios investigados na Bahia, pagavam apenas o salário-mínimo para o ACS. O salário dos médicos 
variava entre $R \$ 3.000,00$ e $R \$ 3.500,00$, enquanto as enfermeiras recebiam entre $R \$ 1.200,00$ e R \$ 2.500,00” (Nunes et al., 2002, p. 1641).

Essa desvalorização material e simbólica reforça a hierarquia estabelecida dentro da ESF, o que tende a obstar o exercício profissional do ACS, que, nas reuniões com a equipe de saúde, deveria ser o representante da população: "A. diz se sentir despreparada para defender sua opinião perto da de um médico. Isso mostra uma hierarquização do trabalho, que causa certa insegurança nas agentes" (reunião, 28 set.). Ao mesmo tempo, há momentos em que defendem os direitos da população: "K. comenta [...] que, em visita a uma instituição de idosos, a ACS desconfiou de maus-tratos e denunciou a situação, que se provou verdadeira" (reunião, 19 out.).

É nesse sentido que alguns autores indicam a importância da dimensão afetiva no exercício profissional dos ACS. O terceiro analisador versa sobre essa questão.

\section{Trabalho afetivo e produção de subjetividade}

Para alguns autores, a dimensão afetiva do trabalho dos ACS estaria associada à sua potencialidade terapêutica, que se revela na capacidade de incidir sobre os processos de produção de subjetividade.

Lancetti (2006) afirma que o que designa os ACS como trabalhadores afetivos fundamentais é o fato de eles não estarem mais enfurnados em consultórios, mas transitando pela região; são cuidadores que se inserem no território existencial da comunidade. Sua escuta atenta e apurada, seu olhar diferenciado, sua postura de acolhimento e sua responsabilidade para com as famílias acompanhadas compõem as sutilezas no trabalho do profissional de saúde. Segundo Merhy e Franco (2003, p. 321), são "formas de abordagens mais relacionais, operando dentro da ideia de que, no encontro entre trabalhador e usuário, este é também sujeito da produção de saúde e pode, dessa forma, ser também protagonista de atos cuidadores, geradores de autonomia".

O encontro dos ACS com os usuários se dá prioritariamente na casa dos munícipes e possibilita a produção de um conhecimento que decorre da identificação e do sentimento de pertença ao lugar. Isso permite que os agentes façam uma triagem e uma coleta de informações muito além daquelas que constam nos prontuários médicos: "M. [...] viu que os remédios que o munícipe tomava estavam todos vencidos ou para vencer. Se ela não tivesse visitado essa residência, talvez a história tivesse tido um desfecho diferente [...]" (reunião, 19 out.).

Assim, uma parte importante das atividades no território é contribuir com o trabalho de uma equipe de saúde no diagnóstico e prognóstico, respeitando a singularidade do caso em suas articulações com as condições culturais, econômicas, sociais e subjetivas. Esse lugar ocupado pelo ACS seria uma possibilidade de sensibilizar a equipe para construir uma visão mais ampla do processo saúde-doença-cuidado, ao produzir uma interferência no que é dado, normatizado e com condutas preestabelecidas (Furlan, 2008).

Contudo, o que foi possível perceber é que há divergências nos modos de perceber e analisar as condições de vida da população pela equipe de saúde. Fazendo visitas domiciliares, o ACS sente na própria pele as agruras e necessidades dos munícipes, ao passo que já enfermeiros e médicos escutam, e não necessariamente planificam uma ação a partir dos dados produzidos pelos ACS em seu encontro com o munícipe: "Essa discrepância de modos de olhar ocorre pela falta de vivência da situação, já que é diferente acompanhar o usuário em casa ou no consultório" (reunião, 17 ago.).

O trabalho domiciliário do ACS cria uma intimidade com a família, ou seja, ao entrar na casa das pessoas, estabelece com elas uma relação permeada de sentimentos e significados: 
"S. diz que nem todos os munícipes agem [...] só pensando neles e esquecendo que os ACS têm sua vida; há algumas famílias que são parte da sua vida, [...] realmente se preocupam com ela também" (reunião, 31 ago.).

Ao mesmo tempo que essa intimidade é essencial ao trabalho, também faz com que os munícipes não consigam distinguir o papel profissional da pessoa que o exerce. Além disso, a dificuldade de esclarecer seu papel como ACS para a população pode acarretar exigências que ultrapassam as atribuições dos agentes.

Muitos dos agentes sentem dificuldade de lidar com essas exigências e também com o eventual falecimento de um munícipe, devido ao forte vínculo construído entre eles: "A. relata que ficou muito chocada com a primeira morte de acompanhado e como foi intenso emocionalmente para ela. [...] ao demonstrar esse sentimento, ouviu dos colegas da equipe que se acostumaria com essa rotina" (reunião, 17 ago.).

A invisibilidade de seus esforços, o não reconhecimento de seus sentimentos e os altos níveis de exigência dos munícipes podem fragilizar o agente, e, se não é reconhecida e acolhida pela equipe de trabalho, essa fragilidade pode reforçar a sensação de impotência, gerando sofrimento no ACS.

Muitas vezes, não há espaço para que esse sofrimento dos ACS seja discutido nas reuniões de equipe, como elemento importante para compreender os casos e o aprimoramento do seu trabalho: "A. diz que há muita falta de compreensão da chefia. Ke. conta que, quando ocorre falecimento de um dos seus acompanhados, se sente triste, mas as outras pessoas [...] não querem saber [...] e seguem trabalhando" (reunião, 31 ago.).

Nesse sentido, o papel do ACS estaria ligado à produção fina e à tecnologia leve, que estão diretamente relacionados à Política Nacional de Atenção Básica a Saúde 5 . Para Mehry e Chakkour (1997), tecnologias leves são as que se expressam no encontro, no trabalho vivo em ato com o usuário final, sendo possível, por meio delas e em suas articulações com as demais tecnologias, dar visibilidade à forma como se tecem as relações, dando pistas sobre o que se dá no interior dos modelos assistenciais de atenção e publicizando as intencionalidades presentes nas práticas de saúde.

Para Campos et al. (2008, p. 133), em função da cultura contemporânea, que valoriza mais o conhecimento do especialista do que do generalista e que impõe respostas rápidas para os problemas encontrados, há uma tendência a desvalorizar os trabalhos que compõem a política de ABS: "A atenção básica, no imaginário de algumas pessoas, ainda remete à noção de menor complexidade, uma vez que se imagina lidar com os problemas simples, os quais requereriam tecnologias menos avançadas e qualificação técnica simplificada". É nesse sentido que o trabalho do ACS também acaba sendo desvalorizado: "Nosso trabalho é [...] de formiguinha, cada um faz uma coisinha" (reunião, 19 out.).

Quando a ACS fala em "formiguinha" pode estar remetendo a certa vulnerabilidade de uma atividade que demanda tempo e um esforço invisível que, muitas vezes, não é reconhecido. De alguma forma, parece que os agentes têm consciência de que seu trabalho não é imediatista, mas construído na delicadeza que necessita de vínculo e cuidado: "M. conta o caso de uma mulher diabética que come de tudo, sem restrição, mas, quando está perante o médico, diz que segue fielmente a dieta. Nessas horas, as ACS contradizem os munícipes para ajudar no tratamento" (reunião, 19 out.).

\footnotetext{
5 Segundo o Ministério da Saúde (Brasil, 2006), a ABS é caracterizada por: "[...] um conjunto de ações de saúde, no âmbito individual e coletivo, que abrangem a promoção e a proteção da saúde, a prevenção de agravos, o diagnóstico, o tratamento, a reabilitação e a manutenção da saúde. É desenvolvida por meio do exercício de práticas gerenciais e sanitárias democráticas e participativas, sob forma de trabalho em equipe, dirigidas a populações de territórios bem delimitados, pelas quais assume a responsabilidade sanitária, considerando a dinamicidade existente no território em que vivem essas populações. Utiliza tecnologias de elevada complexidade e baixa densidade, que devem resolver os problemas de saúde de maior frequência e relevância em seu território".
} 
O que significa que o trabalho afetivo desempenhado pelos ACS ora é desvalorizado, ora é reconhecido, pelas políticas de saúde, pela equipe de saúde, pelos munícipes e pelos próprios agentes. Mas há outras dimensões no trabalho e na vida dos ACS que podem contribuir ou obstar o exercício desse aspecto afetivo. É delas que trata o analisador quatro.

\section{Tão longe e tão perto: as dimensões profissional e pessoal na vida do ACS}

A obrigatoriedade de o ACS residir perto de seu local de trabalho é benéfico para a ESF, já que, fazendo parte da comunidade, o agente conhece bem a população, as potencialidades e as vulnerabilidades da região. Por outro lado, essa proximidade acarreta um sofrimento psíquico adicional aos ACS (Jardim \& Lancman, 2009), que muitas vezes viveram ou ainda vivem as mesmas condições materiais e intelectuais dos munícipes que acompanham.

Uma das agentes relatou o falecimento de seu marido em decorrência da negligência de um médico de um hospital público:

A. [...] procurou uma resposta rápida do médico há pouco tempo e não teve [...] foi por causa do problema de saúde do marido, que já perdeu quase os dois pulmões, porém, os médicos não sabem dizer qual é o problema de saúde dele (reunião, 16 nov.).

Dois dias depois dessa reunião, o marido da agente faleceu, o que nos fez refletir sobre o impacto dessa perda na percepção que os agentes têm do SUS, sistema no qual também atuam como profissionais de saúde.

E está posta a contradição: como profissional de saúde, os próprios ACS relatam que não têm acesso a toda a tecnologia disponível para prolongar a vida, deles próprios e de seus familiares. Mais do que isso, na trajetória de vida desses profissionais, foi possível perceber que há sentimentos de humilhação ${ }^{6}$ relacionados à sua experiência em instituições e ao modo como o Morro foi se configurando como local de moradia para eles e para os seus familiares.

No que se refere à experiência em instituições escolares, K. afirma:

[...] usava um aparelho de coluna e que a diretora olhava com dó para ela e sua familia, que era pobre, e doava material escolar [...] chamava-a de Quixabeira [o sobrenome do pai], e os colegas de sala riam do sobrenome dela [...] diz ter sofrido bastante (reunião, 21 set.).

Nessa mesma direção, A. se emociona ao narrar que, "[...] quando ia à escola, não ganhava material escolar e que sua mãe não tinha condições de comprar, e, quando ia pedir emprestado lápis de cor, as colegas de sala não emprestavam".

Todos os que moram no Morro têm sua história de vida marcada pela história da comunidade. Uma pessoa conta sua tragédia particular: "A casa onde moravam ela, seus seis irmãos e os pais desceu morro abaixo, com as chuvas. Disse que [...] essa história marcou-a muito, pois a família foi separada entre as casas dos vários vizinhos e parentes da região" (reunião, 21 set.). Outras relembram que a região é marcada por vivências de ocupação dos terrenos: "P. [...] disse que mora de aluguel e com os pais [...] chegaram ao morro por invasão [...]. A família ocupou inicialmente a rua Treze, construíram um barraquinho [...]" (reunião, 21 set.).

6 Gonçalves-Filho (1998, p. 11) entende a humilhação social como "uma modalidade de angústia disparada pelo impacto traumático da desigualdade de classes". 
Muitas vezes, os ACS só se percebem partícipes daquela comunidade quando se sentem injustiçados por ter vivido as mesmas condições materiais e intelectuais e não ter tido acesso aos benefícios que os munícipes usufruem atualmente: "Al. disse que, às vezes, a vontade que dá nela é de ficar sem trabalhar para poder fazer os cursos que são oferecidos à comunidade. M. falou que as pessoas que podem fazer os cursos não valorizam essa oportunidade". Essa fala possibilitou que o ACS expressasse sua visão negativa dos munícipes: "[...] disse que não se conforma que hoje as pessoas ficam só pedindo, mas não correm atrás do que precisam; acha que são muito acomodadas" (reunião, 28 set.).

Alguns ACS justificam essa mesma percepção sobre a acomodação das pessoas da comunidade por sua não adesão às propostas de atividades em grupo, pela falta aos exames e às consultas marcadas e pela não observância das orientações da equipe de saúde: "A. diz que têm, sim, casos semelhantes relativos às faltas, reclamando até que os munícipes não utilizam a ESF da maneira como é proposta, pensando que a unidade é um pronto-socorro". Outros consideram os munícipes "preguiçosos": "K. diz que [...] as pessoas têm uma 'renca' de filhos, só querem pedir e não querem trabalhar. [...] diz que, para muitos munícipes, a palavra 'emprego' significa doença" (reunião, 28 set.).

Em outras situações, os ACS percebem que não há como julgar as pessoas da comunidade. A agente M. contou o caso de uma pessoa que não levava os filhos para ser vacinados na unidade de saúde. Ao investigar o caso, descobriu que a mãe das crianças também não havia sido levada para tomar vacinas, na infância: "[...] concluiu dizendo o quanto podemos ser injustos, ao julgar um caso. [...] Explicou para a munícipe que hoje em dia as coisas estão diferentes e esclareceu a importância do acesso aos postos de vacinação" (reunião, 28 set.). Outro ponto também ponderado por M. diz respeito ao fato de que os munícipes sofrem da falta de "[...] informações sobre os seus direitos" (reunião, 28 set.).

Há que ressaltar o modo como os ACS percebem e compreendem as pessoas da comunidade; muitos deles têm dificuldades em problematizar o suposto comodismo à luz das condições materiais de existência dos munícipes. A insistência na visão de que as pessoas são acomodadas parece enfatizar a carência e a falta em detrimento da potência criativa dessa população, que, bem ou mal, tem sobrevivido a inúmeras situações adversas.

Diante disso, vê-se que as diferentes concepções sobre os munícipes podem delinear a prática em saúde dos ACS. Nesse sentido, urge criar espaços em que os agentes possam obter conhecimentos sobre concepções de comunidade do arcabouço técnico e teórico da psicologia comunitária. Rocha e Kastrup (2008, p. 98) defendem a importância de considerar o morador da comunidade "em sua dimensão política e de agente ativo e modificador das estruturas sociais". Transmitir essa ideia aos ACS não parece pouco, pois remete ao fato de que o maior desafio desses profissionais seria enfatizar a potência criativa nos diferentes grupos que compõem a comunidade. Talvez eles pudessem resgatar em seu próprio trabalho e em sua vida a capacidade de fazer frente às situações adversas: "[...] a criação de novas formas de sociabilidade, ou seja, novas maneiras de partilhar o comum, que inevitavelmente esbarram na dimensão política do viver junto".

Por outro lado, compartilhar ou ter compartilhado condições precárias de moradia, muito próximas das condições materiais e intelectuais dos próprios munícipes, faz com que os ACS sofram mais intensamente no cotidiano de seu trabalho. Carreteiro (2003) alerta para o fato de que, na sociedade contemporânea, todos sofrem com a ameaça de exclusão que é permeada pelos imaginários da excelência e da inutilidade. No primeiro, estariam os sujeitos marcados pelo excesso e, no segundo, pela falta. Os sentimentos comuns a todos são o medo e a angústia, advindos da ameaça real de exclusão. Para a autora, os indivíduos que compõem "[...] o imaginário da inutilidade não encontram uma inscrição positivada nos grandes projetos institucionais (educação, saúde, trabalho). As inscrições oferecidas [...] marcam-nos de forma negativa, estabilizando lugares sociais considerados inúteis" (Carreteiro, 2003, p. 60). 
Cabe perguntar se não seria essa a mensagem implícita endereçada ao trabalho do ACS, pelo fato de que seu trabalho é inútil diante dos grandes problemas de sobrevivência e de condições de vida da população atendida - o que implica que os próprios agentes não acreditam no potencial instituinte de suas ações profissionais.

Para a autora, além dos incluídos e dos excluídos, existem pessoas que ocupam um espaço intermediário denominado zona franjal, precariamente posicionadas por meio de subemprego e baixa remuneração. É possível afirmar que os ACS ocupam essa linha imaginária que separa de forma tênue os indivíduos incluídos dos excluídos do sistema capitalista. Parece, assim, que também reavivem situações de precariedade e experiências ameaçadoras, ao entrar em contato com os modos de vida dos munícipes. Mais do que isso, foi possível captar nos registros o processo de precarização do trabalho dos ACS, que o quinto analisador visa a discutir.

\section{Precarização do trabalho do ACS: capacitação, plano de carreira e projeto de vida}

Segundo o Guia Prático da ESF, qualquer munícipe pode se candidatar à vaga de ACS, visto que não é necessário ter experiência na área da saúde. Após sua aprovação, receberá treinamento num curso de capacitação sobre como desenvolver suas atividades e será constantemente orientado pelo enfermeiro/supervisor (Bornstein \& Stotz, 2008).

Furlan (2008, p. 369) afirma que esse é um dos objetivos da ESF: capacitar o agente para detectar as necessidades de saúde da comunidade e, assim, concorrer "para a extensão da atenção à saúde e ampliação do acesso à informação na comunidade". Os relatos dos ACS indicam que a ESF tem tido dificuldades para oferecer cursos que os capacitem para o trabalho na comunidade. A maior parte deles relatou não ter formação técnica, muito menos psicossocial, para trabalhar como agente de saúde. Eles contam como foi começar o trabalho como agente "[...] tiveram apenas três dias de treinamento e depois foram 'jogadas no trabalho' [...] aprenderam sozinhas diversos saberes importantes como o funcionamento da rede de saúde ou as responsabilidades do profissional de cada serviço" (reunião, 17 ago.).

Há também poucas instituições que oferecem esses cursos e poucos agentes que tiveram oportunidade de participar de um deles, e parece que o que tem sido oferecido obedece ao modelo tradicional de aprendizado, totalmente técnico e ainda insuficiente, sem tratar de temas relacionados às angústias do trabalhador de saúde, ao campo de relações e aos diferentes modos de vida: "K. diz que ninguém foi preparado para ser ACS, que o curso só fala a teoria, o que não é suficiente, pois na prática eles não são nada, só na teoria eles têm valor" (reunião, 19 out.). Outra agente recém-contratada fala do curso:

T. relata que o curso que é oferecido não tem a ver com o que de fato os ACS fazem.

Diz que é tudo aparência, pois parece que, no fundo, são apenas aplicadores de pesquisas e fonte para estatísticas, e que, na verdade, o serviço vai além disso (reunião, 16 nov.).

Em diversas falas do ACS do Morro, aparecem questões que fazem coro a condição contraditória da ESF, que se situa entre uma proposta diferenciada para a atenção básica e a redução dos custos de suas atividades. Isso pode confirmar a precarização do trabalho e a falta de reconhecimento das atividades profissionais dos ACS, que pode ser compreendida como um reflexo da desvalorização da própria atenção básica em favor dos outros níveis de atenção em saúde. 
Esse barateamento é, de certa forma, percebido pelos ACS do Morro, pois está associado às dificuldades que eles sentem no cotidiano. Como vimos, queixam-se do excesso de atividades administrativas e de que, apesar do desgaste, ainda ficam com fama de "funcionário público", difundida no senso comum como aquele que tem plano de carreira e emprego vitalício: "M. diz que as ACS não têm reconhecimento, são mão de obra barata, e não são funcionários públicos" (reunião, 19 out.).

O contrato de trabalho dos ACS do Morro é conveniado e tem a mediação de uma Associação da cidade de Santos ${ }^{7}$. Isso parece justificar o fato de se considerar mão de obra barata e sofrerem instabilidade no emprego e precarização do trabalho e não ter plano de carreira.

A falta de investimento na ESF fica também clara para os agentes quando eles comparam a teoria e a prática e questionam a eficácia do SUS, já que seu cotidiano difere muito do que está colocado em seus preceitos: "Nós não estamos fazendo o trabalho que nos cabe, pois ESF é para prevenir, mas virou uma policlínica de um médico só" (reunião, 23 nov.).

É possível arriscar uma hipótese sobre a razão de o lugar diferenciado do ACS estar perdendo espaço para o exercício precarizado de suas atividades. Primeiramente, há uma precarização já determinada por sua formação; os agentes afirmam que: "[...] para concorrer ao cargo de ACS, tem que ter apenas o ensino fundamental, mas, para fazer o curso de capacitação, tem que ter o ensino médio" (reunião, 17 ago.).

Outra questão que podemos trazer para esta discussão: por que o ACS aceita essa situação, mesmo sabendo que sua função está distorcida ou sendo usada como mão de obra barata?

Essa aceitação pode estar relacionada à sensação permanente de ameaça de perda de emprego vivida na comunidade onde mora e trabalha, e isso se refletiria na própria vida dos ACS. Outro ponto a destacar é o fato de que, para a maioria deles, esse emprego seria provisório, pois não há possibilidade de ascensão na carreira, e muitos estão buscando cursos que os ajudariam a conseguir melhores condições de trabalho: "Ke. disse que quer fazer um curso de auxiliar [técnico] de farmácia" (reunião, 28 set.). Outras hipóteses possíveis seriam certo conforto no exercício de funções mais simples, protocolares e burocráticas, pois as ACS não se veem como profissionais, e sim como complementadoras do salário do marido: "K. disse que [...] optou pelo trabalho por causa do filho, pois pode buscá-lo na escola. [...] Que chefe que aceitaria isso, buscar o filho na escola?" (reunião, 28 set.). Esse discurso confirma a dupla ou até tripla jornada de trabalho das mulheres: "[...] pode estender a roupa no varal quando quiser, pode ir recolher a roupa, caso comece a chover, portanto, vê muitas vantagens em trabalhar perto de casa" (reunião, 28 set.). Dos 12 agentes, só 1 é do sexo masculino.

Em síntese, as dificuldades, facilidades e angústias suscitadas pelo trabalho do ACS são questões que devem ser abordadas em reuniões de equipe, que devem se estruturar para contemplar aspectos além dos técnicos do exercício profissional. Devem ser reuniões em que se discutam casos, indiquem as tarefas de cada um da equipe e acompanhem a resolução dos casos pela ESF. Schmidt e Neves (2010, p. 232) confirmam a importância desses espaços coletivos: "Reuniões e supervisões são espaços profícuos para a formação dos agentes e para a mudança de mentalidade de médicos e enfermeiros".

Os próprios agentes verbalizaram essa necessidade:

7 Artigo 1 - Fica autorizado o Poder Executivo a celebrar convênio com a Associação Santista de Pesquisa e Prevenção e Educação - ASPPE, vinculado às normas operacionais do Sistema Único de Saúde, para a execução do Programa de Agentes Comunitários de Saúde - PACS e da ESF, em conformidade com os planos de trabalho a ser apresentados pela entidade para cada exercício e aprovados pela Secretaria Municipal de Saúde. 
[...] apesar de ter problemas, não se abre, pois não sabe como será o acolhimento. [...] diz que se incomoda, já que elas fazem tanto pela saúde dos outros e, quando chega a vez delas, não têm ninguém por elas (reunião, 16 nov.).

O analisador seis versa exatamente sobre o cuidado à saúde do ACS.

\section{Quem cuida dos profissionais cuidadores?}

Os ACS não têm apoio para o desenvolvimento de suas atividades e relatam que não há espaço nas reuniões de equipe para falarem e discutirem o que sentem. A agente M. afirma que "[...] quem cuida deles é Deus, a família e depois eles mesmos" (reunião, 31 ago.), pois o contato direto com situações de vulnerabilidade social faz com que os agentes sejam invadidos por angústias que podem desencadear sentimento de culpa: "[...] a vida dos ACS é permeada por frustrações e angústias, principalmente pelo fato de se sentirem impotentes por não conseguir ultrapassar situações difíceis e proporcionar melhores condições de vida e de saúde para a população [...]" (reunião, 25 jun.). Como exemplo, a ACS A. narrou um caso no qual

[...] a munícipe tem sete filhos [...] não tem emprego, cata papelão e recicla lixo. Os vizinhos denunciaram-na porque saía e deixava os filhos sozinhos em casa, sem comida, com condições minimas de higiene e não os levava para a escola.

A. diz que essa munícipe recebe auxílio do programa Bolsa Família, pretende ter mais filhos e sua vida não mudou nada; tem a impressão de que está só regredindo. Disse, ainda, que os representantes do Conselho Tutelar estão prestes a tirar-lhe a custódia dos filhos: "[...] A. disse não saber o que vai acontecer se tirarem mesmo os filhos da munícipe; disse que há momentos em que sente pena da munícipe, em outros momentos, sente raiva" (reunião, 28 set.).

Todos esses sentimentos desencadeados no contato com situações adversas podem levar o ACS a cobrar a si mesmo pela dificuldade de mudar as condições de vida da população, embora sejam problemas estruturais da sociedade capitalista, que ultrapassam o âmbito de ação desse profissional de saúde. Daí a importância das reuniões de equipe, para que haja clareza sobre o tipo de encaminhamento em cada caso.

Nesse sentido, o sofrimento do ACS pode decorrer desse emaranhado de forças: "Uma série de relatos mostra que não há compreensão [...] por parte da equipe [...] do sentimento de culpa [...]. Quando mostram esses sentimentos, logo seus colegas dizem que eles se acostumarão com essa rotina" (reunião, 17 ago.). Esse tipo de comentário pode levar o ACS a desenvolver um medo de expor suas insatisfações ou queixas: "A. disse que todo mundo queria falar, mas não falava, ou só uma falava, e essa ficava taxada como a ACS ruim, e as outras, que ficaram caladas, eram as boazinhas, ou seja, elas têm medo de se expor" (reunião, 31 ago.).

Outro agravante é que as reuniões de equipe são muitas vezes ocupadas com discussões sobre problemas emergenciais, e as discussões de caso e a escuta das dificuldades do ACS na prática em saúde ficam em segundo plano. M. diz que: "[...] por enquanto, nessas, reuniões elas estão 'apagando o fogo', pois estão respondendo um formulário enviado pela prefeitura, o qual contém questões perguntando sobre o trabalho na ESF" (reunião, 19 out.).

Muitos agentes relatam que sentem medo de enlouquecer em decorrência das exigências do trabalho: "A. contesta essas exigências: 'E como fica a nossa mente?'. Disse que tem dificuldade até para tomar banho, exemplificando esse desgaste vivido por elas" (reunião, 23 nov.). "Al. disse que não quer ser ACS para sempre, pois tem medo de ficar louca" (reunião, 28 set.). Outra agente levanta uma hipótese sobre essa questão: 
Ac. diz que pode ser que essa loucura venha à tona devido ao fato de não ter ninguém para escutá-las e para cuidar delas, e, assim, tem momentos em que elas ficam com muitas coisas na cabeça, o que faz com que cheguem em casa sem disposição para ficar com a família (reunião, 31 ago.).

Muitos ACS têm sua vida invadida pelas preocupações do cotidiano do trabalho, considerando que seu trabalho é relacional: "Muitos agentes acabam levando o problema para sua própria casa, o que interfere em sua vida pessoal" (reunião, 17 ago.). Após esse relato, M. disse que se identificou com a fala da Ac. e desabafou: "[...] achei que era só comigo que isso acontecia. Acredito que, por causa dessas coisas, a profissão de ACS vai entrar em extinção" (reunião, 31 ago.).

$\mathrm{O}$ risco de que a profissão de ACS entre em extinção é real, e, antes que isso aconteça, urge dar-lhe a devida importância, valorizando os agentes como profissionais de saúde. Só assim se fortalece a Estratégia de Saúde da Família como proposta de democratização do acesso aos serviços de saúde.

\section{Considerações finais}

Os maiores avanços da ESF são o trabalho no território, as atividades de promoção e prevenção à saúde e o vínculo e as atividades próximas à comunidade, de alguma forma representados pelo ACS. Mas, apesar de sua potência e seus avanços, a estratégia implica a contradição de ser, ao mesmo tempo, uma política de democratização dos serviços de saúde e certo barateamento das práticas em saúde.

Nesse sentido, o que se produz no cotidiano do serviço é a construção de outro lugar para o ACS, que foge do que é colocado pelas cartilhas do Ministério, e se desvaloriza o saber que entraria na equipe como algo diferenciado no dia a dia. Assim, os agentes procuram se aproximar desse saber conhecido na saúde que lhes daria status e os afastaria da posição de igualdade com seus pares da comunidade. Todavia, essa tentativa fica no meio do caminho, pois, na hierarquia atribuída aos saberes na equipe, o ACS é o menos capacitado, e seu valor na articulação com a comunidade também se torna questionável, pois, na busca desse reconhecimento, o agente pode se ver no lugar de mero cumpridor de tarefas, que não consegue se aproximar e construir uma relação singular com os munícipes que acompanha.

Desse modo, e a partir da visão do ACS sobre suas condições de trabalho, trata-se da necessidade de indicar para as equipes de saúde a importância de apoiá-las nas diversas dimensões de seu trabalho. Entre as formas de apoio está a proposta de reuniões mais amplas, em que os gestores sejam sensibilizados sobre modos de organizar o trabalho na unidade, de modo a dar prioridade às visitas domiciliares sobre as tarefas administrativas. Nesse sentido, urge criar espaços de acolhimento e de escuta para os ACS, colocando-os como importante chave no trabalho da ESF, potencializando sua ação e ressaltando seu lugar privilegiado nessa equipe, privilégio que deve ser acompanhado de melhores salários e um plano de carreira mais condizente com as responsabilidades da função.

Outra condição para manter o lugar privilegiado do agente na equipe de saúde seria a boa interação entre os diferentes profissionais que a compõem, baseada em discussões em conjunto que agregassem os diversos conhecimentos inerentes ao processo saúde, doença e cuidado da população. $O$ que significa que não se trata apenas de cobrar dos ACS o não exercício prático de suas atribuições oficiais, mas que se deve responsabilizar tanto a equipe da unidade de saúde como subsidiária do trabalho do ACS quanto a ESF, que não tem cumprido com uma de suas diretrizes que é a de oferecer cursos de capacitação e educação permanente para esses profissionais. 
No que se refere aos cursos de capacitação, há que cuidar da forma de transmissão dos conhecimentos, como também da escolha dos conteúdos a ser apresentados e discutidos.

Na transmissão dos conteúdos, deve-se dar prioridade às atividades em grupo e aos estudos de caso. Mais do que um repasse de informações vinculado ao modelo tradicional de transmissão de saberes e técnicas, trata-se da construção de espaços de discussão e reflexão sobre as práticas em saúde, de modo que os conhecimentos sejam produzidos coletivamente. Os estudos de casos podem ser uma boa alternativa, já que é na prática que os ACS percebem as dificuldades de encaminhamento e resolução das questões que emergem no cotidiano.

Entre os conteúdos que subsidiariam a atuação do ACS, como já dito anteriormente, é possível citar: a apresentação e a discussão das políticas de saúde e das políticas públicas sociais, bem como dos modos de implantá-las junto à comunidade; o histórico da ABS e da ESF; as concepções de comunidade que enfatizam a potencialidade criativa de seus integrantes; o histórico das desigualdades sociais no capitalismo; o contexto das conquistas na atenção à saúde voltadas às populações menos favorecidas; o papel histórico dos movimentos sociais; a discussão do conjunto de necessidades em saúde; a valorização das ações políticas e inventivas dos munícipes e dos próprios agentes; a apresentação do histórico, da legislação e dos direitos humanos inerentes aos preceitos do SUS, do SUAS (Cras e Creas); e a apresentação das teorias sobre grupos e lideranças comunitárias.

Não se trata de buscar soluções mágicas, mas urge pôr em prática essas ações como único modo de conter o processo de extinção dos agentes comunitários de saúde.

\section{Referências}

Adverse, H. (2010). O que é ontologia do presente? Artigo disponível na Internet: http://www.letras.ufmg.br/nuntius/data1/arquivos/006.09-Helton_Adverse129-152.pdf [25 março 2012].

Bornstein, V. J. \& Stotz, E. N. (2008). Concepções que integram a formação e o processo de trabalho dos agentes comunitários de saúde: uma revisão da literatura. Ciência Eु Saúde Coletiva, 13 (1), 259-268.

Brasil. (1999). Decreto n. 3.189, de 4 de outubro de 1999 (1999, 5 de outubro). Fixa diretrizes para o exercício da atividade de agente comunitário de saúde (ACS), e dá outras providências. Diário Oficial da União, seção 1.

Brasil. (2002). Lei n. 10.507, de 10 de julho de 2002 (2002, 11 de julho). Cria a profissão do agente comunitário de saúde e dá outras providências. Diário Oficial da União, seção 1.

Brasil. (2004). Política Nacional de Assistência Social. Brasília, DF: Ministério do Desenvolvimento Social e Combate à Fome.

Brasil. (2006). Política Nacional de Atenção Básica. Brasília, DF: Ministério da Saúde.

Caiafa, J. (2007). A pesquisa etnográfica. Aventura das cidades: ensaios e etnografias. Rio de Janeiro: FGV.

Campos, G. W. S., Gutiérrez, A. C., Guerreiro, A. V. P. \& Cunha, G. T. (2008). Reflexões sobre a atenção básica e a estratégia de saúde da família. In G. W. S. Campos \& A. V. P. Guerreiro, Manual de práticas de atenção básica: saúde ampliada e compartilhada (pp. 132-153). São Paulo: Hucitec.

Carreteiro, T. C. (2003). Sofrimentos sociais em debate. Psicologia USP, 14 (3), 57-72.

Castro-Silva, C. R., Imbrizi, J. M. \& Garcia, M. L. (2009-2011). Projeto de extensão nos morros Vila Progresso e Santa Maria: a potencialização da capacidade de ação dos agentes comunitários de saúde. Santos, SP: Universidade Federal de São Paulo.

Cecílio, L. C. O. (2001). As necessidades de saúde como conceito estruturante na luta pela integralidade e equidade na atenção. In Pinheiro, R. E. \& Mattos, R. A. Os sentidos da integralidade na atuação e no cuidado em saúde (pp. 113-126). Rio de Janeiro: Abrasco.

Conill, E. M. (2008). Ensaio histórico-conceitual sobre a atenção primária à saúde: desafios para a organização de serviços básicos e da Estratégia Saúde da Família em centros urbanos no Brasil. Cadernos de Saúde Pública, 24 (especial 1), 7-27.

Dejours, C. (1999). O fator humano (2⿳亠丷厂 ed., pp. 39-48). Rio de Janeiro: FGV.

Furlan, P. G. (2008). O agente comunitário de saúde e a prática na atenção básica: alguns apontamentos. In G. W. S. Campos \& A. V. P. Guerreiro. Manual de práticas de atenção básica: saúde ampliada e compartilhada (pp. 368-387). São Paulo, Hucitec.

Gonçalves-Filho, J. M. (1998). Humilhação social: um problema político em Psicologia. Psicologia USP, 9 (2), 11-67. 
Jardim, T. A. \& Lancman, S. (2009). Aspectos subjetivos do morar e trabalhar na mesma comunidade: a realidade vivenciada pelo agente comunitário de saúde. Interface: Comunicação, Saúde e Educação, 13 (28), 123-135.

Lara Junior, N. \& Ribeiro, C. T. (2009). Intervenções psicossociais em comunidades: contribuições da psicanálise. Psicologia ES Sociedade, 21 (1), 91-99.

Kastrup, V. (2008). A cognição contemporânea e a aprendizagem inventiva. In V. Kastrup, S. Tedesco \& E. Passos. Políticas da cognição (pp. 93-112). Porto Alegre: Sulina.

Lancetti, A. (2006). A potência terapêutica dos agentes de saúde. In A. Lancetti (Org.), Clínica peripatética (pp. 8796). São Paulo: Hucitec.

Merhy, E. E. \& Chakkour, M. (1997). Em busca de ferramentas analisadoras das tecnologias em saúde: a informação e o dia a dia de um serviço, interrogando e gerindo trabalho. In Merhy, E. E. \& Onocko, R. (Org.), Agir em saúde: um desafio para o público (pp. 35-78). São Paulo: Hucitec.

Merhy, E. E. \& Franco, T. B. (2003). Por uma composição técnica do trabalho centrada nas tecnologias leve e no campo relacional. Saúde em Debate, 27 (65), 316-323.

Nunes, M. O., Trad, L. A. B., Almeida, B. A., Homem, C. R. \& Melo, M. C. I. C. (2002). O agente de saúde: construção da identidade desse personagem híbrido e polifônico. Cadernos de Saúde Pública, 18 (6), 1639 . 1646.

Passos, E. \& Barros, R. B. (2000). A construção do plano da clínica e o conceito de transdisciplinaridade. Psicologia: Teoria e Pesquisa, 16 (1), 71-79.

Passos, E., Kastrup, V. \& Escóssia, L. (Org.). (2009). Pistas do método da cartografia (pp. 7-205). Porto Alegre: Sulina.

Rocha, T. G. \& Kastrup, V. (2008). A partilha do sensível na comunidade: intersecções entre psicologia e teatro. Revista Estudos de Psicologia, 13 (2), 97-105.

Schmidt, M. L. S. \& Neves, T. F. S. (2010). O trabalho do agente comunitário de saúde e a política de atenção básica em São Paulo, Brasil. Cadernos de Psicologia Social do Trabalho, 13 (2), 225-240.

\section{Endereço para correspondência \\ jaque_imbrizi@yahoo.com.br}

Recebido em 27/09/2011

Revisado em 09/04/2012

Aprovado em 11/04/2012 